\title{
A SYSTEMATIC REVIEW ON EXPERIENTIAL KNOWLEDGE OF WITNESSES USING BEOS PROFILING
}

\author{
Savithri K.K, Dr Priyanka Kacker
}

\author{
M.Phil. Forensic Psychology Student \\ School of Behavioural Sciences, National Forensic Sciences University, Gandhinagar, Gujarat \\ Savithrikk5897@gmail.com \\ Senior Assistant professor \\ School of Behavioural Sciences, National Forensic Sciences University, Gandhinagar, Gujarat \\ drpriyankakacker@gmail.com
}

\begin{abstract}
This review study focuses on a forensic psychological tool, Brain electrical Oscillation Signature Profiling, and its mechanism. In precise, this paper reviews the studies of eyewitness testimony and BEOS in particular. The previous empirical studies and review articles elucidate that BEOS can be used to overcome the effect of internal and external factors in eyewitness testimony. False memory or confabulatory experiences would not affect the accuracy of Brain Electrical Oscillation Signature Profiling. During the trial process, witness testimony can do through BEOS in the future. More empirical researches are necessary for the application of forensic psychology tools in the field of witness testimony.
\end{abstract}

Keywords: BEOS, eyewitness testimony, forensic psychological tools, Witness interrogation

\section{INTRODUCTION}

India, one of the fast-growing countries in the world being appreciated by all other countries for India's diplomacy, economy, good neighbouring, combating against terrorism, and other criminal activities, etc. In India, the criminal justice system is powerful, which is the only institution on which all people can rely firmly. However, there is a high leap in the crime rate. For supporting crime investigation and the criminal justice system, here we have applications of science. Through different areas of science, experts are helping our criminal justice system to give a precise verdict. Forensic Psychology is the application of behavioural science in jurisprudence, helping the crime investigation and court to reveal the truth by using forensic psychological techniques. Forensic psychology is the psychology applied to law. Forensic is a term derived from the Latin word - Forensis, which means concerned with the law. In a broader sense, forensic psychology is the science and application of psychological principles, theories applied to legal issues, all aspects of the law. Forensic Psychology facilitates the detection of deception and crime investigation by using various techniques such as layered voice analysis, polygraph, suspect detection system, and Brain Electrical Oscillation Signature Profiling. Forensic psychology is one of the emerging super-specialty streams in India. It is developing day by day in terms of research, applications in crime investigation, and academic activities. Forensic psychology is not only concentrated on crime investigation, it is also working on crime prevention and offender/victim rehabilitations.

There are different techniques used in crime investigations to detect the deception of offenders. One of the main technologies is a brain lie detector. Brain fingerprinting is one of the technologies detecting the P300 MERMER. This technology is utilized by the FBI and other agencies all over the world. Another technology is Indian-made, known as Brain Electrical Oscillation Signature Profiling is an advanced technology that detects memory related to the crime/event developed by Prof. C.R. Mukundan.

BEOS is working on the principle of experiential knowledge stored in autobiographical memory. BEOS has been using in forensic setup since 2003(Puranik et al 2009). From the birth of BEOS, so many offenders got convicted by the criminal justice system. A lot of innocent people got their normal life back. Brain Electrical Oscillation Signature Profiling is mostly used in suspects and offenders. They are not detecting deception. Perhaps brain lie detectors identify the presence of crime-related memory. However, the BEOS have not explored in witness testimony. Some factors affecting eyewitness testimony accuracy. This could be internal and external factors, but more than that false memory, misinformation, confabulated information, boisterous environment conditions influence the recollection of crime events. Forensic Psychological tool BEOS is also working in the episodic and semantic memory distinction. In this study, the researcher deliberates on the application of Brain Electric Oscillation Signature Profiling in divergent areas of lie detection. The review tries to link between eyewitness testimony and BEOS for a new strategy to testify witnesses inaccuracy. How the 


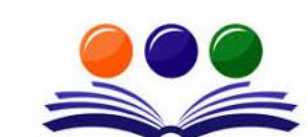

GRAND ACADEMIC PORTAL RESEARCH JOURNALS
GAP iNTERDISCIPLINARITIES A Global Journal of Interdisciplinary Studies

( ISSN - 2581-5628)

Impact Factor: SJIF - 5.047, IIFS - 4.875

Globally peer-reviewed and open access journal.

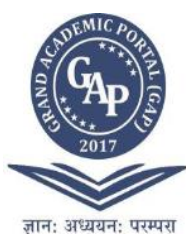

BEOS can be pertinent to other disciplines of the judiciary system. Through this review, the researcher trying to disentangle the vast use of memory-based lie detectors especially the Brain Electrical Oscillation Signature Profiling and the researcher tries to understand the neuropsychological process behind this technology.

\section{EXPOUNDING THE ESSENCE OF BRAIN ELECTRICAL OSCILLATION SIGNATURE PROFILING}

Real Experiences and experiential knowledge of the brain: Experiences can be defined as the confrontation of reality. It can be Personal happenings, emotional encounters, events, or anything that is encountered by a person in their life. This event will record in your brain, especially in your memory. Like experience, knowledge is also stored in our memory. There is a huge difference between knowledge and experience. Experience is our life experienced event or happening, we sensed it and we perceived it. Ultimately it is a personal event. Knowledge is something that we share. In short, knowledge is shared information. Experience is stored in autobiographical memory and knowledge is stowed in our semantic memory. Knowledge is acquired information through books, academic settings, or shared by someone. We have not experienced it, but we knew it.

In that sense, we can say that experiences are real. When a person sees a murder in front of him, that incident which he has been saw is an experience. For that particular event, he will produce experiential knowledge. Experience and knowledge are hellishly associated with human memory. As further whenever we try to recollect our happenings or experiences, actually we are remembering that event. Sensory modalities and motor modalities are intertwined with our experiences. When we recollect the information that we learned without practical involvement or observation, we recall that information. It's a pure semantic memory recall.

\section{REMEMBRANCE AND RECALL: BRAIN MECHANISM OF MEMORY}

Memory is a lively arrangement that gets details from the senses, arranges, and modifies it just the same way it accumulates it off, after which retrieves the details from storages (Alan Baddeley, 1996). Memory is the ability to encode, store, recall information. Brain electrical oscillation signature profile working principle is based on the human memory system. BEOS is constructed on the assessment of two memory systems are semantic memory and autobiographical memory episodes. Knowing which is based on the semantic memory of the individual. Recall of information related to semantic memory can be detected from the activation of some brain areas. Knowing is associated with the activation of the dorso- frontal cortex of the brain. Knowing is the process of recognition. Remembrance is related to autobiographical memory episodes. Remembrance is the autobiographical information is stored in the memory. Remembrance or experiential knowledge is the memory of events experienced by the individual. Stimulation of the anterior cingulated cortex, orbitofrontal cortex, ventral brain, and the medial temporal cortex is associated with remembrance. The experience remembered are mental imageries involving sensory, motor components, proprioceptive, and emotional components. Remembrance involves attending to the internal cognitive processing related to specific events.

Experiential knowledge is connected to long-term memory processing. When we used to recall past events, we utilize episodic memory. Therefore BEOS is measuring the internal processing of remembrance in the brain. Episodic memory stores the information about specific events or episodes related to one's own life. Information about personal experiences is called autobiographical episodes.

\section{RELEVANCE OF MEMORY IN JUDICIARY SETTINGS - EYEWITNESS TESTIMONY}

In judicial settings application of memory is mostly used in eyewitness testimony. Eyewitness affirms what they noticed through his/her experience. That discernment can be either with the unaided human sense or with the manual of an instrument. Eyewitness recollect in a complex manner. Recollection of records about what we have passively seen and what we have actively observed differs. There is a conventional work of Ebbinghaus, which is an experimental method on memory quantity and amount of facts that can reproduce within a period. Consistent with this idea, when time accelerates, retention of information will decrease. A few researchers found the memory traces.

Eyewitness testimony refers to lexical statements from people regarding what they observed and can allegedly remember the crime events during the trial process. Eyewitness identification is a specific type of recognition where the person identifies another person who has been present at the crime scene. Witness recollects a particular action of that person or particular action that occurred in that crime event.

The accuracy of Eyewitness testimony closely depends upon the memory factors of the individual. In almost all memory experiments researchers focused only on memory performance. They forgot to take look at memory as a conscious experience. Here in eyewitness testimony, memory accounts for the conscious experience of events. So that memory, behaviour, knowledge, and experiences are closely correlated (Tulving1989). Conscious experience in memory distinguishes between the knowledge of past events and the recollection of events. 


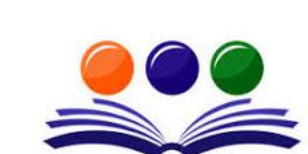

GRAND ACADEMIC PORTAL RESEARCH JOURNALS
GAP iNTERDISCIPLINARITIES A Global Journal of Interdisciplinary Studies

( ISSN - 2581-5628)

Impact Factor: SJIF - 5.047, IIFS - 4.875

Globally peer-reviewed and open access journal.

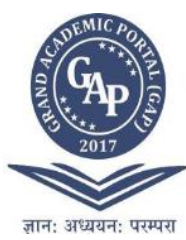

2. Population: Adults, age 18 and older, offenders have participated in previous studies considered as the population for this study. Studies were conducted with adults, from age 18 and older, and offenders were selected.

3. Theoretical perspectives: Theoretical underpinnings of BEOS, Brain waves, Eyewitness testimony, and the Neurological process behind BEOS were extracted from review studies and experimental studies. Most theories were selected from review studies.

4. Case studies: One case study (Puranik et al) of BEOS was selected to know the application of BEOS in different criminal cases.

5. Specific Factors: Experimental studies of BEOS, especially in the investigation of cold crimes, cybercrimes, etc. Brain Oscillation theories and Brain waves information extricated from review studies (Basar et al). The memory influences in eyewitness testimony featured in this review study.

6. Results: In experimental studies of BEOS, experiential knowledge of real experiences is differentiated from knowing experiences. The results could differentiate real experiences from knowing experiences were extracted from experimental studies.

7. Findings: Findings in review studies and experimental studies were accentuated for this review studies, specifically a gap of knowledge.

\section{RESULTS}

Details of the research paper, which discussing brain electrical oscillation signature profiling, development of BEOS, Brain process behind the working of BEOS, and eyewitness testimony, the factors affecting the recollection of an event, are presented in Table 1. (Appendix)

Three studies were used in the same sample population, age 20- 25 years old participants were used in that 3 studies. (Isai, C. \& Kacker 2020, Kacker and Roy, S 2020, Nandini,N. and Kacker,P. 2017 ,TIFAC-DFS Report 2008; Mukundan 2008a, 2008b, 2005; Wagh et al., 2009; Vaya et al. 2009a, b,Kacker, 2018, Isai, C. \& Kacker 2020, Kacker and Roy, S 2020, Nandini,N. and Kacker,P. 2017 , Heuer and Reisberg 1990, Gustafsson, Torun, \& Fredrik, 2019).The theoretical background of BEOS was reviewed from five studies majorly.(Parmar and Mukundan 2017, Mukundan et al 2018, Mukundan et al 2017, Kacker, 2018 Endel Tulving,1989).

Human Brain Oscillations theories were reviewed mainly from two studies by Basar et al 1999, Basar et al 2000. Eyewitness Testimony is affected by internal and external factors. Eyewitness performance can be affected by event factors, retention factors, retrieval factors, and witness factors. Event factors are the duration of the event, frequency of viewing, event complexity, violence, and seriousness. Witness factors such as stress/fear, age, personality characteristics, and expectations. (Wells, 1978) Six research studies were reviewed on Eyewitness testimony, its influencing factors in recollection of memory. (Wells, 1978, Heuer and Reisberg 1990, Gustafsson, Torun, \& Fredrik, 2019, Albright, 2017, Loftus, 2019).

\section{Descriptive Data Synthesis}

The data organized to identify the themes across the studies, that is, theoretical perspectives of Brain electrical Oscillation Signature profiling and its development, processes, Human brain oscillation theories information, and novel application of BEOS in different areas of knowledge, and eyewitness testimony, and affected by the memory factors. (Described in Table 2, appendix)

\section{Theoretical perspectives of Brain electrical Oscillation Signature profiling}

Origin and Theoretical framework: Brain electrical Oscillation Signature Profile/ BEOS is criminal inquisition tool discovered by Prof. C.R. Mukundan, a computer - EEG-based strategy used to detect the presence of remembrance activity in suspects of the crime. BEOS is extracting electrical oscillation signature from the brain by presenting probes. While recalling experiential knowledge, the examinee could recollect the autobiographical information encoded in autobiographical memory related to the happening of the crime or engagement in the crime. (Mukundan CR, 2005)

BEOS is based on the human memory system, so it is a memory-based test and not a deception detection test. BEOS is constructed on the assessment of two memory systems.

- $\quad$ Knowing - It is based on the semantic memory of the subject. By sharing knowledge with others, a person will get semantic information. Knowing is associated with activation from the dorso-frontal cortex.

- Remembrance - Remembrance is the autobiographical information which is encountered in our life. In other words, the events which are faced by the subject are called Remembrance or experiential knowledge. Stimulation of the anterior cingulated cortex, orbitofrontal cortex, ventral brain, and the medial temporal cortex is associated with remembrance.

The meaning behind the name - Brain electrical oscillation signature profile: brain oscillation which elucidates electrical activity of the brain produced during cognitive processing. A signature means a specific pattern of electrical activity while marking the remembrance or experiential knowledge. (Mukundan CR., et al. 2017) 


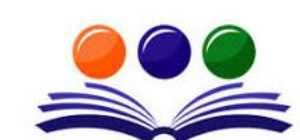

GRAND ACADEMIC PORTAL RESEARCH JOURNALS
GAP iNTERDISCIPLINARITIES A Global Journal of Interdisciplinary Studies

( ISSN - 2581-5628)

Impact Factor: SJIF - 5.047, IIFS - 4.875

Globally peer-reviewed and open access journal.

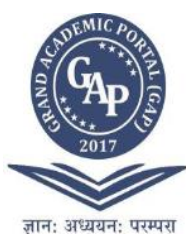

Brain Oscillations or Neural oscillations, which means steady, recurrent electrical impulses of the brain created when neurons get stimulated by spontaneous stimuli. Sensory-cognitive processes are result of brain oscillations (Basar, 2013). Brain oscillations are the functional building blocks of the sensory-cognitive process. Hans Berger is the one who first recorded the human brain in the electroencephalogram. Hans Berger paved the building stone of brain oscillation theory. Berger observed $\sim 10 \mathrm{~Hz}$ rhythmic activity. This electrical activity is the alpha rhythm or Berger rhythm. Brain Oscillation theory developed tremendously with recent updates in the theory. Event-related oscillation in the alpha, delta, gamma, beta, and theta frequency made huge differences in the lie detection area. Especially, gamma oscillation distinguished between true and false memories. Gamma oscillations are related to high-order cognitive processing. Electroencephalogram records 4 types of brain. Delta ranges from 1 to $3.5 \mathrm{~Hz}$, Theta wave ranges from 4 to $8 \mathrm{~Hz}$, Alpha (8 to $13 \mathrm{~Hz}$ ), Beta which ranges from 13 to $30 \mathrm{~Hz}$, and Gamma (30 to 100Hz). Each brain wave has own its functions.

Functions of Brainwaves

- Delta wave is the slow wave with the highest amplitude. Present in children's sleep stages. Delta waves induce growth hormone.

- $\quad$ Theta waves are related to the subconscious activity of the individual. It can be seen in a deep relaxation state and meditation. It encourages the production of the human growth hormone. It accelerates memory and learning.

- $\quad$ Alpha waves are mostly found in the occipital lobe and parietal lobe. Alpha waves can be seen in all adults who are awake or relaxed with closed eyes. "Alpha Coma" is the abnormal case of alpha waves

- $\quad$ Beta is responsible for the behaviours and actions of an individual. Beta wave is related to sensation and perception. It can be mostly found in the temporal lobe and frontal lobe.

- Gamma wave is the high-frequency wave. Gamma is related to perception and consciousness, and hyper-alertness. Gamma waves are associated with higher-order cognitive processes.

\section{Novel Application of BEOS in different knowledge areas}

Isai, C. \& Kacker (2020) conducted a study on the effect of repeated probes in the creation of remembrance, this study brought out that the Remembrance of an individual produced only at the time of an event that registered in the episodic memory of the person himself. Rote learning or repeated listening to the incidents will not elicit experiential knowledge ( Isai, C. \& Kacker 2020).

Human memory is connected to emotion. Positive emotions and negative emotions are capable to make deep impacts on memory. These experiences will produce experiential knowledge of the suspect's memory. In 2018, researchers came across both negative emotion and positive emotion almost equally produces experiential knowledge about the events which made them happy or sad. It was a BEOS based study and 20 participants participated. (Kacker, 2018)

Investigators established the significant role of BEOS in the cyber-crime investigation through their research on the cyber-crime investigation through BEOS profiling. They conducted a study between amateur hackers and professional hackers. Investigators established positivity for the use of BEOS in the cyber-crime investigation. (Kacker and Roy, S 2020)

Nandini,N. and Kacker,P. 2017 conducted a study on the induced paranormal experiences using brain electrical oscillation signature profiling. The study consists of 16 participants. These participants were further divided into experimental and control groups. The experimental group had seen 100 minutes horror video and the control group got the narration of the video. Before recording in BEOS, both groups underwent the paranormal belief test, to measure the level of paranormal belief in participants. All hypotheses formulated in this study are accepted. Researchers found visual imagery recall is influenced by gender differences. The study revealed that the experiment group elicited more visual imagery recall than the control group. Where in the experiment females elicited more visual imagery responses and males elicited more information recall information. The study discovered that females have more paranormal beliefs compared to males.

Kacker \& Amrita, A. (2020) found that experiential knowledge cannot be manipulated with confabulated memory of suspects in the BEOS system. Results found that in BEOS real memories cannot be influenced by false memories.

A study by Pendse, A. \& Kacker, P. 2020 on Cold crime investigation using BEOS discovered that BEOS could use for investigating cold cases. This study was quasi-experimental, and the number of EKs elicited in recent memory, and remote memory was studied and statistically analysed.

\section{Eyewitness Testimony}

As the great philosopher, Bentham said, "Witnesses are the eyes and ears of the justice." Yet there are potential threats to the eyewitness testimony, not actually from the memory factors of the human. Eyewitness testimony refers to verbal statements from people regarding what they observed and can allegedly remember the crime events during the trial process (Wells, 2002). Eyewitness identification is a specific type of recognition where the person identifies another person who has been present at the crime scene. Witness recollects a particular action of that person or particular action that occurred in that crime event. Eyewitness testimony is susceptible to errors and wrong recognition. 


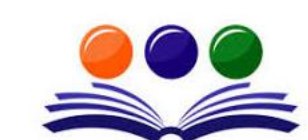

GRAND ACADEMIC PORTAL RESEARCH JOURNALS
GAP iNTERDISCIPLINARITIES A Global Journal of Interdisciplinary Studies

( ISSN - 2581-5628)

Impact Factor: SJIF - 5.047, IIFS - 4.875

Globally peer-reviewed and open access journal.

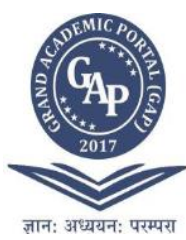

Classical studies in eyewitness testimony were done by Dr. Elizabeth Loftus. She had perturbed about the ensuing facts that could act on the memory of eyewitnesses. The primary focus was on the effect of fallacious information that can be affected through visual representations and usages of terms in eyewitness interrogations. (McLeod, S. A.2014).

Heuer and Reisberg 1990 found that emotion promotes the memory in central information of an event and peripheral in detail. Before this study, the researcher believed that emotion will disrupt memory recollection. Most laboratory studies support the theory that details of emotionally arousing events are not remembered as accurately as details of neutral events; that is a negative emotion leads to generally worse memory (Loftus \& Burns, 1982).

Loftus \& Palmer (1974) found that witnesses to a filmed accident more frequently replied that the accident included broken glass when the question included the phrase "smashed into" rather than the descriptor "hit." The implied content of the question modified the memory of the event.

The experiments conducted by Dr. Loftus provide repeated examples of the fact that witnesses will incorporate post-event misinformation into their memory of an event. If incorrectly informed about the existence of a barn in a film, the witnesses will subsequently provide descriptions of the fictitious building.

Trace theory and the reconstructive view represent opposing approaches to memory. The former advocate's permanent memories are isomorphic with the original experience (e.g., Tulving, 1974). The latter proposes that memories are reconstructed from conceptual schemes (e.g., Bartlett, 1932) to fit the individual's understanding of the event. The eyewitness research bears strongly on this theoretical difference, favouring the reconstructive view.

When we experience an important event, there will be a complex process. This process is divided into 3 stages.

- $\quad$ First, the acquisition stage-the perception of the original event in which information enters a person's memory system.

- $\quad$ Second, there is the retention stage, the period between the event and the eventual recollection of a particular piece of information.

- $\quad$ Third, there is the retrieval stage, during which a person recalls stored information.

Eyewitness performance can be affected by event factors, retention factors, retrieval factors, and witness factors. Event factors are the duration of the event, frequency of viewing, event complexity, violence, and seriousness. Witness factors such as stress/fear, age, personality characteristics, and expectations. (Wells, 1978)

In a chapter named eyewitness recall and testimony, authors have taken an unconventional way to eyewitness testimony. First, they illuminate the distinction between memory- quantity and accuracy of memory. Second, they point up the metacognitive contribution and control processes of memory functioning and witness recall. The authors had strategically analyzed the complexities of the eyewitness testimony. (Pansky, A., Koriat, A., \& Goldsmith, M. 2005.)

Gustafsson, Torun, \& Fredrik, 2019 researched on memory retrieval effort and confidence in eyewitness testimony. According to these researchers, correct memories need less effort than incorrect memories. They found that incorrect memory puts more effort into cue than correct memory. Furthermore, investigators discovered that participants with correct memory have more confidence than participants with incorrect memory.

A study conducted by Albright, 2017 titled "why eyewitnesses fail". It was on the errors that can be happened in eyewitness testimony. National Academy of Sciences assembled a group of experts who have been practicing eyewitness testimony. To know the mistakes and errors that could happen in eyewitness identification. Eventually, these experts found the errors and gave special directions to the judicial system. Loftus, 2019 wrote a special review article on Eyewitness Testimony and published it for the applied cognitive psychology journal. Loftus illuminates the importance and shoots up in the studies of eyewitness testimony. Loftus emphasizes the misinformation in eyewitness testimony and the confidence level of witnesses. Misinformation, confabulation, false memory, memory reconstruction, and emotion, other external factors are affecting the accuracy of eyewitness testimony.

\section{DISCUSSION}

Eyewitness testimony is an important stage of judicial system that could affect by some internal factors and external factors. Eyewitness testimony refers to lexical statements from people regarding what they observed and can allegedly remember the crime events during the trial process. Eyewitness identification is a specific type of recognition where the person identifies another person who has been present at the crime scene. Witness recollects a particular action of that person or particular action that occurred in that crime event.

BEOS is constructed on the assessment of two memory systems. Knowing - It is based on the semantic memory of the subject. By sharing knowledge with others, a person will get semantic information. Knowing is associated with activation from the dorso-frontal cortex. Remembrance is the autobiographical information which is encountered in our life. In other words, the events which are faced by the subject are called Remembrance or experiential knowledge. Therefore, BEOS can be utilized in the field of eyewitness testimony. 


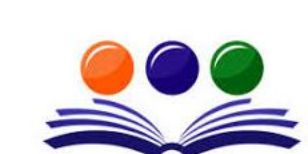

GRAND ACADEMIC PORTAL RESEARCH JOURNALS
GAP iNTERDISCIPLINARITIES A Global Journal of Interdisciplinary Studies

( ISSN - 2581-5628)

Impact Factor: SJIF - 5.047, IIFS - 4.875

Globally peer-reviewed and open access journal.

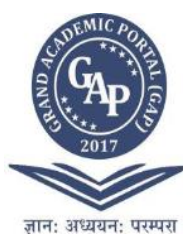

The validity of eyewitness testimony is affected by the misinformation and confabulatory statements given by victims, statements given by eyewitnesses. Amrita,A. and Kacker,P.(2020) found that false memory or confabulated experience will not affect the real experience of the individual, which mean BEOS can differentiate between fake witness and true witness. BEOS is applicable in eyewitness testimony to overcome the issues of misinformation, false memory, and confabulatory experiences.

\section{CONCLUSION}

Brain Electrical Oscillation Signature profiling (BEOS) is a forensic psychological advanced technology to detect the offenders by assessing their experiential knowledge. BEOS has been constructed on the assessment of two memory systems. Knowing - It is based on the semantic memory of the subject. By sharing knowledge with others, a person will get semantic information. Remembrance is the autobiographical information which is encountered in our life. In other words, the events which are faced by the subject are called Remembrance or experiential knowledge. The validity of eyewitness testimony is affected by the misinformation and confabulatory statements given by victims, statements given by eyewitnesses. False memory or confabulated experience will not affect the real experience of the individual. As per the prior studies and reviews, BEOS can be used in the field of eyewitness testimony. Further, empirical researches should be done on this particular area to explore and execute different forensic psychological tools in the judicial system that will make judiciary execution more precise.

\section{REFERENCES}

[1] Albright, T. D. (2017). Why eyewitnesses fail. Proceedings of the National Academy of Sciences, 114(30), 7758-7764. doi:10.1073/pnas.1706891114

[2] Bartlett, F.C. Remembering. Cambridge: The University Press, 1932.

[3] Başar E. (2013). Brain oscillations in neuropsychiatric disease. Dialogues in clinical neuroscience, 15(3), 291-300. https://doi.org/10.31887/DCNS.2013.15.3/ebasar

[4] Başar, E. (2008). Oscillations in "brain-body-mind"-A holistic view including the autonomous system. Brain Research, 1235, 2-11. doi:10.1016/j.brainres.2008.06.102

[5] Bibin Abraham Zachariah,Dr. S.L. Vaya, Bijin Thomas Zachariah, Brain fingerprinting technology (BFP) and brain electrical oscillation signature (BEOS): which unique technique is best?, Global Journal for Research Analysis: Voulme -6,Issue -12,December 2017.

[6] Charan Isai,P. and Kacker,P.(2020). Effect of repeated probes on creating experientialknowledge.

[7] Deffenbacher, K. 1983. The influence of arousal on reliability of testimony. In Evaluating Witness Evidence: Recent Psychological Research and New Perspectives, ed. SMA Lloyd-Bostock, BR Clifford, pp. 235-51. Chichester, Engl.: Wiley

[8] Grandhi, S R \& Kacker, P. (2020). Cyber Crime Investigation Through BEOS Profiling,GAP INTERDISCIPLINARITIES A Global Journal of Interdisciplinary Studies, VOLUME - III ISSUE II, page no. 67-72, ISSN - 2581-5628, UGC Care Listed, Impact Factor: SJIF - 5.047, IIFS - 4.875

[9] Heuer,F.,Reisberg,D. Vivid memories of emotional events: The accuracy of rememberedminutiae.Memory\&Cognition 18, 496506(1990).https://doi.org/10.3758/BF03198482

[10]Isai, C. \& Kacker, P. (2020) Effect Of Repeated Probes On Creating Experiential Knowledge, GAP INTERDISCIPLINARITIES A Global Journal of Interdisciplinary Studies, Volume - III Issue III June - August 2020, Pg. 17-29, ISSN - 2581-5628, Impact Factor: SJIF - 5.047, IIFS - 4.875

[11]Jensen, Ole \& Spaak, Eelke \& Zumer, Johanna. (2014). Human Brain Oscillations: From Physiological Mechanisms to Analysis and Cognition. 10.1007/978-3-642-33045-2_17.

[12] Kacker P. \& Ajitprasad A. (2020) Experiential Knowledge On Confabulated And Real Experiences Using Neuro-Signature System: A Pathway To Criminal Justice, GAP INTERDISCIPLINARITIES A Global Journal of Interdisciplinary Studies, Volume - III Issue III June - August 2020, Pg. 30-36, ISSN - 2581-5628 Impact Factor: SJIF - 5.047, IIFS - 4.875

[13] Kacker P. Experiential knowledge of positive and negative experiences on remembrance and neural response using neuro signature system. J Clin Psychiatry Cog Psychol 2018;2(1):19-25. DOI: $10.35841 /$ clinical-psychiatry.2.1.19-25

[14] Kacker P. Experiential knowledge of positive and negative experiences on remembrance and neural response using neuro signature system. Journal of Clinical Psychiatry Cognitive Psychology 2018;2(1):1925. 


\title{
GAP iNTERDISCIPLINARITIES
} A Global Journal of Interdisciplinary Studies

\author{
( ISSN - 2581-5628 ) \\ Impact Factor: SJIF - 5.047, IIFS - 4.875 \\ Globally peer-reviewed and open access journal.
}

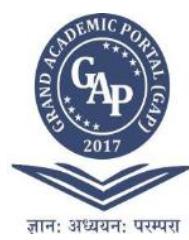

[15]Kacker, P. \& Pandya, A. (2020) Forensic Psychology For Prevention Of Crime And Rehabilitation Of Offenders: Public Health Perspectives; GAP Indian Journal Of Forensics And Behavioural Sciences, Volume I Issue I January - June 2020, Pg. 5-7

[16]Lindholm, T., \& Christianson, S.-åke. (1998). Gender effects in eyewitness accounts of a violent crime. Psychology, Crime \& Law, 4(4), 323-339. doi:10.1080/10683169808401763

[17] Loftus EF, Loftus GR, Messo J. 1987. Some facts about “weapon focus.” Law Hum. Behav. 11:55-62

[18] Loftus, E. F. (2019). Eyewitness Testimony. Applied Cognitive Psychology. doi:10.1002/acp.3542

[19] Loftus, E.F. Eyewitness testimony. Cambridge, Massachusetts: Harvard University Press, 1979a.

[20]Loftus, E.F. Impact of expert psychological testimony on the unreliability of eyewitness identification. Journal of Applied Psychology, 1980, 65, 9-15.

[21] Loftus, E.F. The malleability of human memory. American Scientist, 1979b, 67, 312-320.

[22]Loftus, E.F., \& Loftus, G. On the permanence of stored information in the human brain. American Psychologist, 1980, 35, 409-420.

[23] Martin, J. A., Cohen, J., \& Stokes, A. (2018). Understanding and Evaluating Eyewitness Recall of Events. Proceedings of the Human Factors and Ergonomics Society Annual Meeting, 62(1), 421425. doi:10.1177/1541931218621096

[24]McLeod, S. A. (2014, January 11). Loftus and Palmer. Simply Psychology. https://www.simplypsychology.org/loftus-palmer.html

[25] Mukundan CR and Kacker P. (2019) Arousal and drive - Cognitively Molded Emotional Arousal. EC Neurology 11.1: 12-20.

[26] Mukundan CR, Sumit S, Chetan SM. Forensic Applications of Recording the Neurocognitive Processes of Remembrance. Peer Re J Foren \& Gen Sci 2(3)- 2018. PRJFGS.MS.ID.000140. DOI: 10.32474/PRJFGS.2018.02.000140

[27] Mukundan CR. (2005). Brain electrical oscillation signature profiling for forensic applications. International Conference of Association of Forensic Sciences, 21-26.15.

[28] Mukundan CR. (2007). Brain Experience: Neuroexperiential Perspectives of Brain-Mind. Atlantic Publishers, New Delhi, India.

[29] Mukundan CR. (2008). BEOS Profiling in Crime Investigation. Abstract, the Annual Conference of Division of Forensic Psychology. British Psychological Society, 24-26. 14.

[30] Mukundan CR., et al. (1989): Changes in the amplitude spectrum of fast EEG frequencies in cognitive processing. Pharmacopsychoecologia 2, 1-2, 49-55.5.

[31] Mukundan CR., et al. (2017). Brain Electrical Oscillations Signature Profiling (BEOS) for Measuring the Process of Remembrance. EC Neurology 8.6, 217-230

[32] Mukundan, C.R, Ajayan, P, Kacker, P, Chetan, S. M., Vyas, J. M. (2014).Violent Behavior: Absence of Social Conditioning of Drives during Neurodevelopmental Stages. The International Journal of Indian Psychology, Special Issue 2014, Vol 2, Issue 1, Redshine Publication Inc., ISSN: 2349-3429. Impact Factor: 0.363

[33] Mukundan, C.R. \& Kacker, P. (2020). Brain And Mind: Mind Created From The Brain - Dependent On Material: Scientific Principles And Relationships In The Brain, And On The Independently Created Mind Relationships And Principles, GAP Indian Journal Of Forensics And Behavioural Sciences, Volume I Issue I January - June 2020, Pg. 62-65.

[34] N. Nandini and Kacker, P. (2017). Paranormal Movie Based 'Experiential Knowledge' using BEOS Profiling. Indian Journal of Health \& Wellbeing. Vol 8, 11 (2017), 1285-1290.

[35]N. Nandini, Kacker, P. (2017) Paranormal Movie Based “Experiential Knowledge" using Brain Electrical Oscillations Signature (BEOS) Profiling. Indian Journal of Health and Wellbeing, Vol. 8, No. 11.

[36]Pansky, A., Koriat, A., \& Goldsmith, M. (2005). Eyewitness Recall and Testimony. In N. Brewer \& K. D. Williams (Eds.), Psychology and law: An empirical perspective (p. 93-150). The Guilford Press.

[37]Pendse, A \& Kacker, P. (2020) Remembrance of Recent Vs. Remote Memory of an Event: A Key to Investigation of Cold Cases, The Indian Police Journal, Volume 67, Number , January-March, 2020, pg: 8995

[38] Puranik, D.A., Joseph, S.K., Daundkar, B.B., Garad, M.V. (2009). Brain Signature profiling in India. It's status as an aid in investigation and as corroborative evidence - as seen from judgments. Proceedings of XX All India Forensic Science Conference, 815 - 822, November 15 - 17, Jaipur.

[39]Roy, G.S., and Kacker, P. (2019). Cyber Crime Investigation through BEOS Profiling. https://www.gapinterdisciplinarities.org/res/articles/67-72.pdf. 


\section{GAP iNTERDISCIPLINARITIES}

\section{A Global Journal of Interdisciplinary Studies}

( ISSN - 2581-5628)

[40]Tekcan, A., Yilmaz, E., Kızılöz, B.K., Karadöller, D.Z., Mutafoğlu, M., \& Erciyes, A.A. (2015). Retrieval and phenomenology of autobiographical memories in blind individuals. Memory, 23, 329 - 339.

[41]TIFAC-DFS-PROJECT-FINAL-REPORT. (2008). Normative Data for Brain Electrical Activation Proling. Research project by DFS, Gandhinagar and Funded by Technology Information Forecasting \& Assessment Council (TIFAC), New Delhi.

[42] Tulving, E. (1989). Memory: Performance, knowledge, and experience. European Journal of Cognitive Psychology, 1(1), 3-26. doi:10.1080/09541448908403069

[43] Tulving, E. Cue-dependent forgetting. American Scientist, 1974, 62, 74-82.

[44]Vaya, S.L., (2013, 2nd edi.). National Resource Center For Forensic Psychology. Directorate of Forensic Science. Gandhinagar.

[45]Wells, G. L. 1978. "Applied Eyewitness-Testimony Research: System Variables and Estimator Variables," Journal of Personality and Social Psychology 36:1546-57.

[46]Wells, G. L., and R. C. L. Lindsay. 1980. "On Estimating the Diagnosticity of Eyewitness Nonidentification," Psychological Bulletin 88:776-84.

[47]Wells, G. L., M. R. Leippe, and T. M. Ostrom. 1979. "Guidelines for Empirically Assessing the Fairness of a Lineup," Law and Human Behavior 3:285-94.

[48]Wells, G. L., R. C. L. Lindsay, and J. P. Tousignant. 1980. "Effects of Expert Psychological Advice on Human Performance in Judging the Validity of Eyewitness Testimony," Law and Human Behavior. In press.

[49]Wells, G. L., R. C. L. Lindsay, and T. J. Ferguson. 1979. "Accuracy, Confidence, and Juror Perceptions in Eyewitness Identification, "Journal of Applied Psychology 64:440-48.

[50]Wixted, J. T., Mickes, L., \& Fisher, R. P. (2018). Rethinking the Reliability of Eyewitness Memory. Perspectives on Psychological Science, 13(3), 324-335. doi:10.1177/1745691617734878

[51]Yuille, J.C. A critical examination of the psychological and practical implications of eyewitness research. Law Hum Behav 4, 335-345 (1980). https://doi.org/10.1007/BF01040625 